RESEARCH REPORT

\title{
Association between home smoking restrictions and changes in smoking behaviour among employed women
}

\author{
Donald R Shopland, Christy M Anderson, David M Burns
}

J Epidemiol Community Health 2006;60(Suppl II):ii44-ii50. doi: 10.1136/jech.2006.045724

See end of article for authors' affiliations

.....................

Correspondence to: Mr D R Shopland, 312 Meadowview Lane, Ringgold, GA 30736, USA; e-mail: reedonald@ aol.com

Accepted for publiction 10 June 2006

\begin{abstract}
Study objective: Examine trends in home smoking restrictions among employed women not living alone and assess the associations of such restrictions with smoking behaviour.

Design: Multivariate logistic regression analysis of major demographic variables and household composition characteristics.

Study participants: 128024 employed female respondents to the Census Bureau's current population survey over the 10 year period 1992 to 2002.

Main results: The prevalence of smoke free homes has increased significantly over the past decade. This increase was evident across all demographic and household characteristics examined with the greatest rate of increase seen among smoking households. Nearly $90 \%$ of households consisting of all never smoking adult members reported having a smoke free home in 2001-02 compared with 22\% of households consisting of all smokers. The extent of smoking restrictions in the home was the most powerful determinant of cessation of all the factors examined in the regression model. Odds of becoming a former smoker (any length) and quit for three months or more were seven to eight times greater among those women reporting their homes were smoke free compared with those whose homes permitted smoking anywhere in the home.

Conclusions: Smoke free homes were associated with a highly significant increase in quitting $(p<0.0001)$. However, at this time it is not clear what proportion of the observed effect can be attributed to living in a smoke free home. None the less, the significantly increased probability of quitting correlated with having a smoke free home found in this analysis, are substantially higher than the odds reported in most workplace studies published to date; additional studies are needed to elucidate this relation.
\end{abstract}

$E$ xposure to secondhand smoke is an important cause of premature death and disability among non-smokers. Secondhand smoke is linked to an increased risk for lung cancer and coronary heart disease as well as asthma and other respiratory tract infections and sudden infant death syndrome. ${ }^{1-5}$ The California Environmental Protection Agency (CalEPA), in a newly released report on the health consequences of secondhand smoke, estimated that secondhand smoke is responsible for roughly 50000 non-smoker deaths annually in the USA, mostly from heart disease. ${ }^{6}$ The two important sources of secondhand smoke exposure for most of the US adult population, are home and the workplace; while the home is the predominant source of exposure for children. ${ }^{56}$

Seventy per cent of USA indoor workers now report that their place of employment is smoke free ${ }^{7}$ and a considerable scientific database currently exists on workplace smoking policies and their potential to influence smoking behaviour of workers. ${ }^{8-11}$ Even the tobacco industry's own research has confirmed the importance of smoke free workplace policies for decreasing consumption and increasing a worker's ability to successfully stop smoking. ${ }^{12}$ In contrast, far less is known about the potential of a smoke free home environment to influence smoker behaviour.

The data in this paper were presented at the September 2005 conference "Tobacco control policy and low socioeconomic status (SES) women and girls" held in Bethesda, $\mathrm{MD}$ and therefore focuses almost exclusively on a female population although limited data on men are presented for comparison purposes in the Discussion.

We examine trends in the prevalence of smoke free homes among employed women and the association between such restrictions and changes in smoking behaviour. We also examine some factors associated with adoption of a smoke free home policy. We used data from a series of cross sectional surveys conducted by the US Census Bureau for the National Cancer Institute over the 10 year period 1992 to 2002.

\section{METHODS}

Each month the US Census Bureau collects labour force and demographic information from about 50000 US households as part of its ongoing current population survey (CPS). The complete CPS methodology is published elsewhere. ${ }^{13}$ Briefly, in 1992 the National Cancer Institute (NCI) sponsored a 40 item Tobacco Use Supplement to the CPS (TUS-CPS) that collected, among other things, information on current cigarette use patterns, quitting behaviour, workplace smoking policies, and rules about smoking in the home. NCI sponsored supplements were conducted in three designated months during four overlapping calendar year periods, 199293; 1995-96; 1998-99; and 2001-02.

On the CPS, all household members ages zero and greater are enumerated, and all household members ages 15 and above are interviewed. This allows the data to be organised and analysed by household characteristics such as whether all adult members of the household are smokers, nonsmokers, or mixed (containing both smokers and nonsmokers).

These analyses are restricted to adult female self respondents, ages 18 years of age and older. To give greater meaning to the presence of smoking restrictions in the home, we confined the analyses to respondents who did not live alone. Similarly, because we were interested in investigating the association between worksite restrictions and adoption of 
Table 1 Prevalence and odds ratios (OR) of having a smoke free home. Employed adult women (age 18 and older) who do not live alone. CPS 1992-93 and 2001-02

\begin{tabular}{|c|c|c|c|c|c|c|}
\hline \multirow[b]{2}{*}{ Variable } & \multicolumn{3}{|l|}{$1992-93$} & \multicolumn{3}{|l|}{$2001-02$} \\
\hline & $\begin{array}{l}\% \text { Smoke free } \\
(95 \% \mathrm{Cl})\end{array}$ & $\begin{array}{l}\text { OR } \\
(95 \% \mathrm{Cl})\end{array}$ & $p$ Value & $\begin{array}{l}\text { \% Smoke free } \\
(95 \% \mathrm{CI})\end{array}$ & $\begin{array}{l}\text { OR } \\
(95 \% \mathrm{Cl})\end{array}$ & p Value \\
\hline \multicolumn{7}{|l|}{ Household smoking status } \\
\hline All smokers & $5.5(4.8,6.2)$ & 1.00 & & $22.0(20.4,23.5)$ & 1.00 & \\
\hline Mixed at least one smoker & $19.6(18.9,20.3)$ & $1.87(1.60,2.18)$ & $<0.0001$ & $44.9(43.5,46.3)$ & $1.38(1.20,1.59)$ & $<0.0001$ \\
\hline Former smokers & $51.8(50.9,52.7)$ & $6.46(5.50,7.58)$ & $<0.0001$ & $80.7(79.8,81.5)$ & $5.12(4.37,5.99)$ & $<0.0001$ \\
\hline All never smokers & $66.3(65.3,67.2)$ & $9.70(8.07,11.67)$ & $<0.0001$ & $88.2(87.6,88.9)$ & $7.58(6.44,8.92)$ & $<0.0001$ \\
\hline Unknown & $42.7(40.7,44.7)$ & $4.84(4.03,5.82)$ & $<0.0001$ & $69.4(67.5,71.3)$ & $3.17(2.70,3.72)$ & $<0.0001$ \\
\hline \multicolumn{7}{|l|}{ Individual smoking status } \\
\hline Daily smoker & $6.8(6.2,7.4)$ & 1.00 & & $22.6(21.4,23.8)$ & 1.00 & \\
\hline Occasional smoker & $19.3(17.6,20.9)$ & $2.70(2.33,3.13)$ & $<0.0001$ & $48.6(45.4,51.8)$ & $2.79(2.39,3.25)$ & $<0.0001$ \\
\hline Former smoker & $41.7(40.6,42.9)$ & $2.71(2.40,3.07)$ & $<0.0001$ & $72.7(71.6,73.8)$ & $3.04(2.69,3.43)$ & $<0.0001$ \\
\hline Never smoker & $56.0(55.2,56.7)$ & $3.63(3.18,4.15)$ & $<0.0001$ & $82.0(81.5,82.5)$ & $3.80(3.40,4.25)$ & $<0.0001$ \\
\hline \multicolumn{7}{|l|}{ Education } \\
\hline$\leqslant 12$ years & $33.5(32.7,34.2)$ & 1.00 & & $59.9(59.0,60.9)$ & 1.00 & \\
\hline $13-15$ years & $44.1(43.0,45.2)$ & $1.28(1.21,1.36)$ & $<0.0001$ & $70.7(69.7,71.7)$ & $1.40(1.30,1.51)$ & $<0.0001$ \\
\hline $16+$ years & $57.5(56.6,58.5)$ & $1.63(1.55,1.72)$ & $<0.0001$ & $81.5(80.7,82.3)$ & $1.68(1.56,1.82)$ & $<0.0001$ \\
\hline \multicolumn{7}{|l|}{ Race/ethnicity } \\
\hline White & $40.2(39.5,40.9)$ & 1.00 & & $67.3(66.6,68.0)$ & 1.00 & \\
\hline Hispanic & $56.2(54.3,58.1)$ & $1.72(1.56,1.90)$ & $<0.0001$ & $81.7(79.9,83.5)$ & $1.81(1.56,2.09)$ & $<0.0001$ \\
\hline African-American & $41.1(39.8,42.4)$ & $0.93(0.87,0.99)$ & 0.0184 & $68.2(66.5,70.0)$ & $0.78(0.71,0.86)$ & $<0.0001$ \\
\hline Asian-Pacific Islander & $66.4(63.6,69.2)$ & $2.09(1.81,2.42)$ & $<0.0001$ & $82.4(79.9,84.9)$ & $1.42(1.15,1.76)$ & 0.0016 \\
\hline Native American & $33.9(26.8,40.9)$ & $1.07(0.78,1.47)$ & 0.6724 & $59.2(52.4,66.0)$ & $0.90(0.65,1.25)$ & 0.5327 \\
\hline \multicolumn{7}{|l|}{ Workplace smoking restrictions } \\
\hline No policy, smoking permitted & $35.6(34.7,36.4)$ & 1.00 & & $60.2(67.2,68.6)$ & 1.00 & \\
\hline Smoke free & $48.5(47.6,49.4)$ & $1.41(1.33,1.50)$ & $<0.0001$ & $72.5(71.8,73.1)$ & $1.43(1.33,1.53)$ & $<0.0001$ \\
\hline \multicolumn{7}{|l|}{ Homes with young children } \\
\hline No children $<5$ & $40.8(40.1,41.5)$ & 1.00 & & $67.9(67.2,68.6)$ & 1.00 & \\
\hline Children $<5$ & $47.7(46.5,49.0)$ & $1.25(1.15,1.36)$ & $<0.0001$ & $75.6(74.5,76.8)$ & $1.37(1.24,1.52)$ & $<0.0001$ \\
\hline \multicolumn{7}{|l|}{ Household composition } \\
\hline Multiple adults, no children & $40.7(39.7,41.7)$ & 1.00 & & $66.6(65.6,67.5)$ & 1.00 & \\
\hline Multiple adults, children & $44.6(43.9,45.3)$ & $1.10(1.04,1.16)$ & 0.0025 & $72.8(72.0,73.6)$ & $1.23(1.14,1.33)$ & $<0.0001$ \\
\hline One adult, children & $38.1(36.0,40.2)$ & $0.84(0.74,0.94)$ & 0.0036 & $67.6(66.1,69.0)$ & $0.97(0.87,1.09)$ & 0.6530 \\
\hline \multicolumn{7}{|l|}{ Age } \\
\hline $18-24$ & $44.1(42.5,45.8)$ & 1.00 & & $68.6(66.9,70.3)$ & 1.00 & \\
\hline $25-44$ & $43.1(42.4,43.8)$ & $0.89(0.82,0.96)$ & 0.0027 & $70.8(70.1,71.5)$ & $0.87(0.78,0.98)$ & 0.0211 \\
\hline $45-64$ & $39.2(38.0,40.4)$ & $0.86(0.79,0.94)$ & 0.0011 & $67.5(66.6,68.4)$ & $0.79(0.71,0.88)$ & $<0.0001$ \\
\hline $65+$ & $42.7(38.8,46.6)$ & $0.95(0.77,1.17)$ & 0.6407 & $69.7(65.8,73.6)$ & $0.89(0.72,1.10)$ & 0.2809 \\
\hline \multicolumn{7}{|l|}{ Occupation } \\
\hline White collar & $45.1(44.4,45.8)$ & 1.00 & & $72.1(71.5,72.6)$ & 1.00 & \\
\hline Service worker & $35.9(34.4,37.4)$ & $1.02(0.94,1.10)$ & 0.6462 & $61.9(60.4,63.3)$ & $0.92(0.85,1.00)$ & 0.0642 \\
\hline Blue collar & $29.7(28.3,31.1)$ & $0.79(0.73,0.85)$ & $<0.0001$ & $58.3(56.0,60.5)$ & $0.78(0.70,0.86)$ & $<0.0001$ \\
\hline
\end{tabular}

rules about smoking in the home, we also limited the analyses to employed indoor workers only $(\mathrm{n}=128024)$.

Women with missing responses for independent and dependent variables comprised less than $5 \%$ for all surveys (range $1.6 \%$ to $4.6 \%$ ) and thus were eliminated from the analysis.

\section{DEFINITIONS AND MEASURES}

The definition of smoke free used in this analysis is identical to that used in previous studies. ${ }^{9-11}{ }^{14-18}$ For workplace policies, those workers who reported that their employer had an official policy restricting smoking and that the policy did not permit smoking anywhere in the public or common areas of their place of employment or in work areas, were labelled "smoke free". All other responses were combined into a single category and labelled "smoking allowed".

Home environments were labelled "smoke free" if subjects responded that "no one is allowed to smoke anywhere" in the home. Other response choices included "smoking is allowed in some places or at some times" and "smoking is permitted anywhere". In the data below these are labelled, "some smoking allowed" and "allowed anywhere", respectively.

\section{Cessation measures}

In our analysis, we use two measures of cessation, "quit smoking any length" and "quit smoking 3+ months." The first measure (quit any length) includes former smokers of all durations, and therefore is the broadest measure of success because it will include large numbers of people who relapse. ${ }^{19}$ Quit attempts lasting three or more months duration (quit 3 + months) provides a measure of longer term successful abstinence. Fully two thirds of smokers who relapse do so within 90 days, many within the first week after a quit attempt. ${ }^{20}$

To examine changes in smoking behaviour over the past year, smoking status at time of the survey was analysed in relation to their self reported smoking status one year before survey administration, and the analyses were limited to those women who reported being daily smokers one year before the survey. Smokers were classified by the extent to which they reported different smoking behaviours at the two points in time, particularly by whether they were a former smoker (any duration) or former smoker who had been quit for three or more months at the time of the survey. The definition used to define a current or former smoker in this analysis is identical to the definition used on most federally sponsored surveys. Respondents who reported smoking at least 100 cigarettes in their lifetime and were still smoking every day at the time of interview were considered "current daily smokers;" respondents who reported having smoked 100 cigarettes in their lifetime but were no longer smoking at the time of interview were classified as "former smokers."21-23 


\section{Other measures}

In addition to demographic characteristics of education, race/ ethnicity, and age, respondents were characterised by several household attributes. Households with children younger than 5 years of age were identified as were the composition of adults and children in each household. We created three categories of household composition: multiple adults, no children; multiple adults, children; and one adult, children. In the analysis of home smoking restrictions, households were additionally classified into four categories: all smokers; mixed (at least one current smoker in household); mixed former (at least one former smoker in household, no current smokers); all never smokers. In some households, not all adults were surveyed, and these households were classified as "unknown".

\section{Analyses}

The TUS-CPS provides weights for self respondents that can be used to produce population estimates. Because about 5\% of the households in this analysis had more than one female indoor worker who responded to questions about restrictions in their home, their corresponding weights were scaled back by the number of qualified respondents in the household, so that these households would not be overrepresented.

Logistic regression was used to investigate the relation between smoke free homes and smoke free worksites, controlling for household smoking status, individual smoking status, education, race/ethnicity, household composition, age, and occupation.

Each of the four cessation measures was modelled separately using multiple logistic regression. Variances for the analyses were obtained using SUDAAN (release 9.01) to account for the complex survey design effect of the CPS
(Research Triangle Institute, Research Triangle Park, NC, 2005).

\section{RESULTS}

The prevalence of having a smoke free home has increased significantly during the 10 year period 1992 to 2002 (table 1). This increase was evident across all of the categories of household smoking status, demographics, and household composition characteristics.

Households with all never smokers reported the highest frequency of smoke free homes, increasing to nearly 9 of 10 such households by 2001-02, a relative change of $+33 \%$. However, even households with all smokers reported a substantial increase in such policies. Barely 1 in 20 of these households were smoke free in 1992-93. This proportion increased to slightly more than 1 in 5 by 2001-02, a relative change of $+300 \%$. The same pattern was seen when trends were examined by the smoking status of the person rather than the household. The highest frequencies of reported smoke free households were seen among female never smokers with daily smokers reporting the lowest frequency but the largest percentage increase. The importance of smoking status (either household or person) in influencing the odds of having a smoke free home was also confirmed in the multiple logistic regression modelling.

Prevalence of a smoke free home increased with increasing level of educational attainment. More than 8 of 10 respondents with a college degree or higher reported having a smoke free home by 2001-02 compared with 6 of 10 among those with a high school education or less. It is interesting to note, however, that the frequency of having a smoke free home reported by those with the least amount of education in 2001-02 is slightly greater than that reported by those with

Table 2 Odds of quitting smoking any length. Multiple logistic regression analysis. Employed adult women (age 25 and older) who do not live alone and who were daily smokers one year ago. CPS 1992-93 and 2001-02

\begin{tabular}{|c|c|c|c|c|}
\hline \multirow[b]{2}{*}{ Variable } & \multicolumn{2}{|l|}{ 1992-93 } & \multicolumn{2}{|l|}{ 2001-02 } \\
\hline & OR $(95 \% \mathrm{Cl})$ & $p$ Value & OR (95\% Cl) & $\mathrm{p}$ Value \\
\hline \multicolumn{5}{|l|}{ Home smoking restrictions } \\
\hline Smoking permitted & 1.00 & & 1.00 & \\
\hline Some smoking permitted & $2.15(1.70,2.73)$ & $<0.0001$ & $2.34(1.54,3.55)$ & $<0.0001$ \\
\hline No smoking permitted & $7.77(5.91,10.21)$ & $<0.0001$ & $6.54(4.61,9.28)$ & $<0.0001$ \\
\hline \multicolumn{5}{|l|}{ Education } \\
\hline$\leqslant 12$ years & 1.00 & & 1.00 & \\
\hline $13-15$ years & $1.07(0.85,1.36)$ & 0.5599 & $1.39(1.02,1.89)$ & 0.0394 \\
\hline $16+$ years & $1.22(0.95,1.57)$ & 0.1208 & $2.17(1.44,3.27)$ & 0.0003 \\
\hline \multicolumn{5}{|l|}{ Race/ethnicity } \\
\hline White & 1.00 & & 1.00 & \\
\hline Hispanic & $0.99(0.48,2.03)$ & 0.9848 & $0.50(0.20,1.21)$ & 0.1206 \\
\hline African-American & $0.74(0.49,1.13)$ & 0.1570 & $0.88(0.49,1.57)$ & 0.6660 \\
\hline Asian-Pacific Islander & $0.87(0.36,2.07)$ & 0.7419 & $1.40(0.49,4.03)$ & 0.5231 \\
\hline Native American & $0.72(0.25,2.12)$ & 0.5464 & $1.73(0.60,5.00)$ & 0.3034 \\
\hline \multicolumn{5}{|l|}{ Workplace smoking restrictions } \\
\hline No policy, smoking permitted & 1.00 & & 1.00 & \\
\hline Smoke free & $1.02(0.83,1.26)$ & 0.8549 & $1.11(0.81,1.53)$ & 0.5144 \\
\hline \multicolumn{5}{|l|}{ Homes with young children } \\
\hline No children $<5$ & 1.00 & & 1.00 & \\
\hline Children $<5$ & $0.72(0.54,0.97)$ & 0.0324 & $1.10(0.70,1.74)$ & 0.6647 \\
\hline \multicolumn{5}{|l|}{ Household composition } \\
\hline Multiple adults, no children & 1.00 & & 1.00 & \\
\hline Multiple adults, children & $0.78(0.61,1.00)$ & 0.0468 & $0.75(0.53,1.07)$ & 0.1166 \\
\hline One adult, children & $1.00(0.71,1.40)$ & 0.9854 & $0.61(0.41,0.91)$ & 0.0152 \\
\hline \multicolumn{5}{|l|}{ Age } \\
\hline $25-44$ & 1.00 & & 1.00 & \\
\hline $45-64$ & $0.90(0.72,1.13)$ & 0.3493 & $0.76(0.55,1.07)$ & 0.1116 \\
\hline $65+$ & $0.63(0.21,1.86)$ & 0.3912 & $2.09(0.75,5.85)$ & 0.1570 \\
\hline \multicolumn{5}{|l|}{ Occupation } \\
\hline White collar & 1.00 & & 1.00 & \\
\hline Service worker & $0.74(0.59,0.94)$ & 0.0136 & $0.78(0.53,1.17)$ & 0.2268 \\
\hline Blue collar & $0.66(0.50,0.86)$ & 0.0028 & $0.71(0.44,1.15)$ & 0.1649 \\
\hline
\end{tabular}


16 or more years of education in the baseline survey of 1992$93(59.9 \% \vee 57.5 \%)$. Education also emerges as a significant factor in the multiple logistic regression modelling with an odds ratio slightly greater than 1.6 for 16+ years of education compared with high school or less.

Race and ethnicity was a less important factor in determining home smoking restrictions, although Asian/ Pacific Islander and Hispanic women reported significantly higher rates of having a smoke free household than did other racial/ethnic groups in both 1992-93 and 2001-02. The difference was significant in the logistic regression models as well. In 1992-93 Asian/Pacific Islander women reported a 10 percentage point higher frequency of a smoke free home than did Hispanic women, but by 2001-02, the prevalence of smoke free homes among Hispanics and Asian/Pacific Islanders was essentially identical, with 8 of 10 reporting such a home environment.

Variables associated with a lower prevalence of having a smoke free home include: employment in a worksite where smoking is permitted, living in a household with multiple adults and no children, employment in a blue collar occupation, and living in a household with no children under the age of 5 . Some variation was seen by age, with women under age 25 having a higher odds of reporting a smoke free home than women ages $25-64$ in the logistic regression models.

\section{Home smoking rules and quitting behaviour}

The associations of home smoking restrictions and cessation behaviour is examined in tables 2 and 3 that present the results of a multiple logistic regression analyses for two cessation measures: (1) odds ratios of being a former smoker of any duration (table 2) and (2) of being a former smoker of $3+$ months (table 3 ). These analyses were limited to those subjects who were daily smokers one year before interview, not living alone, and who were age 25 and older. The age limitation was used to reduce the number of smokers who might still be in the process of initiation, which would make it difficult to interpret any change seen in their smoking status. Also, by age 25, most women have completed their formal schooling and have entered the workforce. Because we were primarily interested in assessing the association between the degree of home smoking restrictions and quitting, the home smoking restrictions variable included three measures: (1) those homes that prohibit smoking anywhere in the home (smoke free), (2) those in which smoking is permitted in some areas or at some times (some smoking allowed), and (3) those in which smoking is permitted anywhere in the home (smoking permitted).

In addition to home smoking rules, other factors included in the model were: level of education, race/ethnicity, workplace restrictions, homes with young children, household composition, age, and occupation. Smoking restrictions in the home and the extent of those restrictions are the most powerful predictors of cessation of all the factors examined in the regression models for both survey years (tables 2 and 3 ). The odds ratios for becoming a former smoker (any length) or having quit for $3+$ months increased with increasing level of home smoking restriction in both survey years. These results are highly statistically significant and the increase is of a large magnitude (tables 2 and 3).

Women living in homes where some smoking is permitted were more than twice as likely to be a former smoker of three or more months duration in both 1992-93 and 2001-02 compared with those living in homes permitting smoking anywhere in the home. Odds ratios for quitting for $3+$ months were seven or greater among respondents reporting a smoke free home compared with those living in homes where

Table 3 Odds of quitting smoking for three or more months. Multiple logistic regression analysis. Employed adult women (age 25 and older) who do not live alone and who were daily smokers one year ago. CPS 1992-93 and 2001-02

\begin{tabular}{|c|c|c|c|c|}
\hline \multirow[b]{2}{*}{ Variable } & \multicolumn{2}{|l|}{ 1992-93 } & \multicolumn{2}{|l|}{ 2001-02 } \\
\hline & OR $(95 \% \mathrm{Cl})$ & $p$ Value & OR $(95 \% \mathrm{Cl})$ & $\mathrm{p}$ Value \\
\hline \multicolumn{5}{|l|}{ Home smoking restrictions } \\
\hline Smoking permitted & 1.00 & & 1.00 & \\
\hline Some smoking allowed & $2.18(1.63,2.92)$ & $<0.0001$ & $2.45(1.48,4.07)$ & 0.0007 \\
\hline No smoking permitted & $7.41(5.55,9.90)$ & $<0.0001$ & $7.08(4.45,11.26)$ & $<0.0001$ \\
\hline \multicolumn{5}{|l|}{ Education } \\
\hline$\leqslant 12$ years & 1.00 & & 1.00 & \\
\hline $13-15$ years & $1.05(0.80,1.38)$ & 0.6973 & $1.46(0.99,2.16)$ & 0.0581 \\
\hline $16+$ years & $1.18(0.85,1.62)$ & 0.3115 & $2.18(1.29,3.68)$ & 0.0041 \\
\hline \multicolumn{5}{|l|}{ Race/ethnicity } \\
\hline White & 1.00 & & 1.00 & \\
\hline Hispanic & $1.24(0.59,2.61)$ & 0.5618 & $0.36(0.09,1.41)$ & 0.1402 \\
\hline African-American & $0.87(0.51,1.47)$ & 0.5870 & $1.17(0.61,2.23)$ & 0.6330 \\
\hline Asian-Pacific Islander & $0.93(0.31,2.81)$ & 0.8977 & $0.61(0.05,8.04)$ & 0.7003 \\
\hline Native American & $1.19(0.41,3.46)$ & 0.7437 & $2.18(0.61,7.82)$ & 0.2280 \\
\hline \multicolumn{5}{|l|}{ Workplace smoking restrictions } \\
\hline No policy, smoking allowed & 1.00 & & 1.00 & \\
\hline Smoke-free & $1.30(1.04,1.63)$ & 0.0214 & $0.99(0.67,1.45)$ & 0.9397 \\
\hline \multicolumn{5}{|l|}{ Homes with young children } \\
\hline No children $<5$ & 1.00 & & 1.00 & \\
\hline Children $<5$ & $0.74(0.53,1.04)$ & 0.0853 & $1.09(0.62,1.92)$ & 0.7744 \\
\hline \multicolumn{5}{|l|}{ Household composition } \\
\hline Multiple adults, no children & 1.00 & & 1.00 & \\
\hline Multiple adults, children & $0.69(0.52,0.93)$ & 0.0143 & $0.70(0.46,1.06)$ & 0.0897 \\
\hline One adult, children & $0.74(0.50,1.11)$ & 0.1424 & $0.67(0.42,1.07)$ & 0.0916 \\
\hline \multicolumn{5}{|l|}{ Age } \\
\hline $25-44$ & 1.00 & & 1.00 & \\
\hline $45-64$ & $0.87(0.66,1.16)$ & 0.3408 & $0.86(0.60,1.25)$ & 0.4272 \\
\hline $65+$ & $0.61(0.16,2.30)$ & 0.4535 & $2.43(0.70,8.44)$ & 0.1584 \\
\hline \multicolumn{5}{|l|}{ Occupation } \\
\hline White collar & 1.00 & & 1.00 & \\
\hline Service worker & $0.67(0.49,0.92)$ & 0.0140 & $0.91(0.57,1.47)$ & 0.6986 \\
\hline Blue collar & $0.69(0.46,1.04)$ & 0.0748 & $0.62(0.33,1.19)$ & 0.1488 \\
\hline
\end{tabular}


smoking was permitted anywhere in the home (table 3). A similar pattern is seen for cessation of any length-that is, those respondents reporting no home smoking restrictions had a lower odds of quitting for any length of time, followed by those who permitted some smoking.

Odds of longer term cessation (quit three or more months) generally increased with increasing level of education. However, this was significant only in 1998-99 (data not shown) and 2001-02. Having a smoke free worksite was somewhat associated with quitting 3+ months in 1992-93 (OR 1.30 CI 1.04, 1.63) but not in subsequent surveys. Race/ ethnicity, age, household composition, households with children under age 5, and occupation were also not associated with an increased odds ratio for either cessation measure and this was true across both surveys.

\section{DISCUSSION}

The prevalence of home smoking restrictions has increased dramatically over the past decade, and a clear majority of homes are now smoke free. Trends in home restrictions parallel trends seen in the workplace where the percentage of US indoor workers reporting a smoke free place of employment increased from just $3 \%$ of workers in $1986^{14}$ to $46 \%$ in $1992-93^{15}$ and to $71 \%$ by $2001-02 .{ }^{7}$

These changes in home and workplace smoking restrictions are largely responsible for the significant decline in serum cotinine concentrations (a metabolite of nicotine) found among US non-smokers ages 3 and above between 1988-91 and 1999-00. ${ }^{24}$ According to the third national report on human exposure to environmental chemicals, mean cotinine concentrations declined $68 \%$ in children, $69 \%$ in adolescents, and $75 \%$ in adults during this time period. ${ }^{24}$

In this analysis of employed women not living alone, the prevalence of smoke free homes increased significantly among every demographic and household characteristic examined with the largest proportional increases occurring among smokers and smoker related households, although these groups still lag significantly behind others in the reported frequency of such restrictive policies. Nearly $90 \%$ of households composed of all never smokers were smoke free by 2001-02 compared with just $22 \%$ of households with all current smokers.

Smoking status of the household was the strongest predictor of adopting a smoke free home policy, followed by smoking status of the person. Households composed of all never smokers were 7 tol 0 times more likely to have a smoke free home than were households composed of all current smokers. Those mixed households composed of a least one former smoker but no current smokers were five to six times more likely to adopt such a policy, and those mixed households with at least one current smoker were less than twice as likely to have a smoke free home than all smoker households. Odds ratios for having a smoke free home were 2.0 or less among all remaining variables examined.

In this analysis we attempted to look at the association between home smoking restrictions and two measures of cessation: cessation for any length of time and cessation of three or more months. Logistic regression modelling shows that women who were daily smokers 12 months previously are much more likely to be quit at the time of the survey as well as to have been abstinent for $3+$ months if they have a smoke free home. After controlling for a number of demographic and household characteristics including age, education, race/ethnicity, worksite policies, household composition, and occupation, home smoking restrictions were more highly correlated with both cessation measures than were any other characteristic or variable examined. Odds ratios of being quit and being quit for 3+ months were between seven and eight times greater among women living in no smoking households compared with those living in households where smoking was permitted anywhere in the home. The odds ratios for these cessation measures among women living in homes where smoking is permitted in some areas of the home were over two times higher than women who lived in homes where smoking is permitted anywhere in the home.

Because these data focus exclusively on women, we undertook a separate analysis of men in an effort to see if a similar pattern is found. The analytical approach used for men was identical to that used for women (see methods section). Overall, the pattern we found for women was also seen among men. The percentage of men who reported having a smoke free home was similar to the percentage reported by women and this was true across all variables and for both points in time. Similarly, those variables in the multiple regression analysis that were associated with a statistically significant higher odds of having a smoke free home among women were also significant among men, with one important distinction, male odd ratios for having a smoke free home were greater than the odds ratios among women when the data are analysed by the smoking status of the household but slightly lower than the odds ratio in women when the data are examined by the smoking status of the person.

Findings from the multiple logistic regression modelling of quitting any length and quitting $3+$ months, were also similar in both sexes. For example, in 2001-02, an odds ratio of 4.95 (CI 3.43, 7.15) for quitting any length and 7.58 (CI 4.46, 12.89) for quitting 3+ months, was found among those men reporting a smoke free home compared with men reporting no home smoking restrictions. The corresponding odd ratios for women were 6.54 (CI 4.61,9.28) and 7.08 (CI 4.45,11.26) for quitting any length and quitting $3+$ months, respectively.

The primary goal of any policy banning smoking is to protect non-smokers from a known health risk. Smoke free policies have an added benefit, which is to help reduce smoking prevalence and increase cessation. Studies have consistently shown that smoke free workplace policies can substantially reduce daily cigarette consumption, increase cessation, and aid in the cessation process by providing a more supportive environment for those smokers making a quit attempt. ${ }^{20}$ Although the preponderance of studies published to date have focused on the workplace, evidence is now beginning to accumulate on the correlation between home smoking restrictions and changes in smoker behaviour among both adults ${ }^{25-31}$ and adolescents..$^{32-34}$

Analysing data from the earlier 1992-93 CPS, Farkas et al found a statistically significant correlation between home smoking restrictions and both quit attempts and successful quitting, defined as quit for six or more months, among more than 48000 adult smokers; furthermore, household restrictions were more strongly correlated with both cessation outcomes compared with workplace restrictions. ${ }^{25}$ Using a stages of change model Pizacani et al conducted a 21 month follow up of 565 smokers to assess the association between home smoking restrictions and changes in smoking behaviour. Odds ratios above 4.0 were seen for both 7 day and 90

\section{Policy implications}

If the association between a smoke free home and quitting behaviour proves real, programmes promoting adoption of such policies could become just as important as programmes promoting workplace smoking restrictions for reducing smoking prevalence while helping to eliminate non-smoker exposure to the health risks of secondhand smoke. 
day smoking abstinence but only among those smokers classified as being in the preparation stage at baseline. ${ }^{26}$ Another study based on a stage of change model conducted among a small sample of inner city black smokers participating in a community cessation programme $(n=311)$, reported higher odds of adopting home smoking restrictions with increased progress in stages of change. ${ }^{27}$ Gilpin et al investigated the association between home smoking restrictions and smoking behaviour among a random sample of Californian adult smokers in 1996. Intention to quit in next six months was significantly associated with restrictive home policies but only among those smokers whose family expressed a preference that the smoker did not smoke. They concluded that restrictions were associated with a higher frequency of recent quit attempts and that such policies seem to prolong time to relapse after cessation. ${ }^{28}$ In a second Californian study, smokers with a home smoking ban were more likely to have made a quit attempt in the past year than smokers without a home ban but this effect was not statistically significant (OR 1.80 CI 0.94, 3.37). However, smokers living in a smoke free household consumed significantly fewer cigarettes per day and were twice as likely to be interested in quitting compared with smokers with no home restrictions. ${ }^{29}$

Australian investigators conducted a subsample analysis of 2526 respondents to the 1998 national drug strategy household survey and found the odds of having quit smoking were 4.5 times greater among respondents who lived in households where smoking was not permitted than for those living in homes with no restrictions. ${ }^{30}$

In addition to adults, a limited number of studies have assessed the impact of home smoking restrictions on the smoking status of adolescents. In general, these studies found home smoking restricts were associated with several positive outcomes, including a reduced likelihood of adolescent initiation, an increased odds of being a former smoker, or being in an earlier stage of smoking update, compared with adolescents who lived in households with no restrictions. ${ }^{32-34}$

Although, the association between smoke free homes and cessation in our analysis was highly significant $(\mathrm{p}<0.0001)$, it is not clear to what degree these differences in cessation can be directly attributed to the adoption of restrictive home policies. It is unknown, for example, how much of the association seen is attributable to women who quit because they live in a smoke free home and how much is attributable to women who are in the process of quitting adopting rules prohibiting smoking anywhere in the home. Farkas and colleagues postulate three ways in which home restrictions could be correlated to changes in behaviour: (1) restrictions, more specifically total bans, may actually cause changes in smoker behaviour; (2) changes in behaviour may lead to adoption of restrictive home policies particularly in an effort to reduce recidivism - that is, people who are contemplating a quit attempt may declare their homes smoke free in an effort to improve their chances of long term success; and (3) both quitting and adoption of home smoking restrictions may occur simultaneously both for relapse prevention and to eliminate exposure to a known health threat for the benefit of other household members and non-smoking guests-many people may simply ban smoking in the home

\section{What this paper adds}

The sevenfold to eightfold greater odds of quitting smoking for three or more months associated with a smoke free home found in this analysis is significantly greater than the odds of quitting found in most workplace studies and deserves further investigation. concurrent with or immediately after cessation, in an effort to reduce smoking cues and thereby reduce their odds of relapse. ${ }^{25}$

Findings in this analysis are subject to several limitations. Firstly, the study population involves a unique subpopulation of employed women not living alone and thus may not apply to women in general. Secondly, the data are cross sectional, not longitudinal, and thus can only provide limited insight into the possible causal association between restrictive home policies and quitting behaviour of smokers reporting such policies. Thirdly, reporting bias and smoker misclassification cannot be ruled out. As smoking prevalence and the social acceptability of cigarette smoking continues to decline, people may feel pressured to provide socially desirable responses, particularly in households with young children. ${ }^{26}$ Mumford and colleagues, analysing 1998-99 CPS data, estimated that $12 \%$ of sample households provided inconsistent reports about home smoking bans, with multimember smoker households substantially less likely to consistently report home bans. ${ }^{35}$ A similar finding was reported among a sample of Californian smokers by Gilpin et al where responses were concordant in $82 \%$ of cases. However, among discrepant responses, the discrepancy was more likely that the smoker reported no home smoking restrictions whereas other household members reported the presence of restrictions. ${ }^{28}$ Finally, all data analysed in this report are based on self reports, including changes in smoking status, without biochemical validation. To what degree misrepresentation of smoking status occurs among self reported former smokers participating in large national surveys is unclear. In a metaanalysis of 30 published reports on the validity of self reported smoking involving samples ranging from several hundred to several thousand, Patrick et al found that studies comparing self reported smoking status with results of biochemical validation were generally high, especially among observational studies using interviewer administered questionnaires, with sensitivity and specificity levels for self reports approaching $90 \%{ }^{36}$ A conclusion similar to that reached in the 1990 surgeon general's report on the benefits of quitting. ${ }^{37}$

None the less, the sevenfold to eightfold greater odds of quitting for three or more months associated with a smoke free home found in this analysis is significantly greater than the odds of quitting found in most workplace studies ${ }^{8-11}$ and merits further investigation. Most home restrictions are adopted voluntarily while worksite policies are almost always imposed through regulation, either mandated by legislation, or decisions imposed by management..$^{38} 39$

An extensive literature base clearly shows that smoke free workplace policies are strongly correlated with various changes in smoker behaviour, including a number of important reviews on the topic. $^{8} 101140-42$

To what degree workplace smoking restriction may influence adoption of home smoking restrictions has not received as much attention by the scientific community. Gower and colleagues, analysing two earlier waves of the CPS, found an association between working in a smoke free place of employment and a higher prevalence of reported smoking restrictions in the workers' homes. Less than a smoke free policy at work was not associated with adoption of home smoking restrictions. ${ }^{11}$ Australian investigators conducted a logistic regression analysis on over 17000 respondents to the 1998 NSW health study and found being employed in smoke free workplaces increased the likelihood of having a smoke free home for both current and former smokers $(\mathrm{OR}=1.6, \mathrm{OR}=1.2$ respectively $) .{ }^{43} \mathrm{~A}$ finding similar to ours for women, $(\mathrm{OR}=1.4$ for smokers and non-smokers combined) at both baseline and 10 years later. Male odds ratios were 1.5 at both points in time. Finally, home smoking restrictions can also provide a supportive social environment 
to remain abstinent from smoking, similar to that seen for workplace restrictions, by reducing cues and messages that encourage smoking and thereby reduce chances of relapse. ${ }^{44}$

Some state tobacco control programmes, such as those in California, have conduced periodic mass media and educational programmes in an effort to educate the public about the dangers of secondhand smoke in the home, and the US Environmental Protection Agency has sponsored an ongoing national educational campaign asking adult smokers to "take a smoke-free home pledge" as a means of reducing the risks of childhood asthma associated with exposure to secondhand smoke. ${ }^{29} 4546$

If the association between a smoke free home and quitting behaviour identified in our analysis proves real, programmes promoting adoption of such policies could become just as important as programmes promoting workplace smoking restrictions for reducing smoking prevalence while helping to eliminate non-smoker exposure to the health risks of secondhand smoke. Such a finding would have strong implications for health care workers and public health officials alike, especially those involved in programmes that reach families with small children and women who are pregnant.

\section{Authors' affiliations}

D R Shopland, US Public Health Service (retired), Ringgold, USA

C M Anderson, D M Burns, Tobacco Control Policies Project, University of California at San Diego, San Diego, USA

Funding: financial support was provided by the American Legacy Foundation, Washington, DC, and the William Kahan Distinguished Professorship from the Flight Attendant Medical Research Foundation, Miami, FL

Conflicts of interest: none.

\section{REFERENCES}

1 US Department of Health and Human Services. The health consequences of involuntary smoking. A report of the surgeon general, 1986. Washington, DC: US DHHS, PHS, CDC, 1986

2 National Academy of Sciences. Environmental tobacco smoke. Measuring exposures and assessing health effects. Washington, DC: National Research Council, National Academy Press, 1986.

3 US Environmental Protection Agency. Respiratory health effects of passive smoking: lung cancer and other disorders. The report of the US Environmental Protection Agency. Bethesda, MD: US DHHS, PHS, NIH, 1993.

4 International Agency for Research on Cancer. Tobacco smoke and involuntary smoking. Lyon: IARC, 2004

5 California Environmental Protection Agency. Health effects of exposure to environmental tobacco smoke. The report of the California Environmental Protection Agency. Bethesda, MD: US DHHS, PHS, NIH, 1999.

6 California Environmental Protection Agency. Proposed identification of environmental tobacco smoke as a toxic air contaminant. Sacramento, CA Cal EPA, Air Resources Board, Office of Environmental Health Hazard Assessment, 2005, http://www.arb.ca.gov/toxics/ets/finalreport/ finalreport.htm

7 Plescia MG, Malek SH, Shopland DR, et al. Protecting workers from secondhand smoke in North Carolina. NC Med J 2005:66:184-9.

8 Fichtenberg CM, Glantz SA. Effect of smoke-free workplaces on smoking behaviour: systematic review. BMJ 2002;325:188-91.

9 NIOSH. Work, smoking, and health. Atlanta, GA: US DHHS, PHS, CDC, 2002.

10 Burns DM, Shanks TG, Major JM, et al. Restrictions on smoking in the workplace. In: Population based smoking cessation. Proceedings of a conference on what works to influence cessation in the general population. Bethesda, MD: US DHHS, PHS, NIH, 2000

11 Gower KB, Burns DM, Shanks TG, et al. Workplace smoking restrictions, rules about smoking in the home, and attitudes toward smoking restrictions in public places. National and state-specific estimates from the current population survey. In: State and local legislative action to reduce tobacco use. Bethesda, MD: US DHHS, PHS, NIH, 2000

12 Heironimus J. Impact of workplace restrictions on consumption and incidence. Inter-office correspondence, 9 Jan 1992. Philip Morris document 2045447779. http://www.pmdocs.com.

13 US Department of Commerce. Current population survey. Design and methodology. Washington, DC: US Census Bureau, 2000.

14 Gerlach KK, Shopland DR, Hartman AM, et al. Workplace smoking policies in the US. Results from a national survey of over 100,000 workers. Tob Control 1997;6:199-206
15 Shopland DR, Gerlach KK, Burns DM, et al. State-specific trends in smoke-free workplace policy coverage. J Occup Environ Med 2001;43:680-6.

16 Shopland DR, Anderson CM, Burns DM, et al. Disparities in smoke-free workplace policies among food service workers. J Occup Environ Med 2004;46:347-56.

17 Center for Disease Control. Passive smoking: beliefs, attitudes, and exposures B United States, 1986. MMWR 1988;37:239-41.

18 Centers for Disease Control. State-specific prevalence of current cigarette smoking among adults and the proportion of adults who work in a smoke-free environment, United States 1999. MMWR 2000;49:978-82.

19 Burns DM, Anderson CM, Johnson M. et al. Cessation and cessation measures among adult daily smokers: national and state specific data, In: Population based smoking cessation. Bethesda, MD: US DHHS, PHS, NIH, 2000:25-97.

20 US Department of Health and Human Services. The health consequences of smoking: nicotine addiction. A report of the surgeon general. Washington, DC: US DHHS, PHS, CDC, 1988

21 Centers for Disease Control. State-specific prevalence of cigarette smoking and quitting among adults-United States, 2004. MMWR 2005:55:1124-7.

22 Centers for Disease Control. Cigarette smoking among adults - United States, 2003. MMWR 2005;54:509-13.

23 Shopland DR, Hartman AM, Gibson JT et al. Cigarette smoking among US adults by state and region: estimates from the current population survey. J Natl Cancer Inst 1996;88:1748-58.

24 US Department of Health and Human Services. Tobacco smoke. In: Third national report on human exposure to environmental carcinogens. Atlanta GA: US DHHS, PHC, CDC, 2005.

25 Farkas A, Gilpin EA, Distefan JM, et al. The effects of household and workplace smoking restrictions on quitting behavior. Tob Control 1999;8:261-5.

26 Pizacani BA, Martin DP, Stark MJ, et al. A prospective study of household smoking bans and subsequent cessation related behaviour: the role of state of change. Tob Control 2004;13:23-9.

27 Okah FA, Okuyemi KS, McCarter KS et al. Predicting adoption of home smoking restrictions by inner-city black smokers. Arch Pediatr Adolesc Med 2003;157:1202-5

28 Gilpin EA, White MM, Farkas AJ, et al. Home smoking restrictions: which smokers have them and how they are associated with smoking behavior. Nicotine Tobacco Research 1999;1:153-62.

29 Norman GJ, Ribisi KM, Howard-Pitney B, et al. The relationship between home smoking bans and exposure to state tobacco efforts and smoking behaviors. Am J Health Promotion 2000;15:81-8.

30 Siahpush M, Borland R, Scollo M. Factors associated with smoking cessation in a national sample of Australians. Nicotine Tobacco Research 2003:5:597-602.

31 Honjo K, Tsutsumi A, Kawachi I, et al. What accounts for the relationship between social class and smoking cessation? Results of a path analysis. Soc Sci Med 2006;62:317-28.

32 Farkas AJ, Gilpin EA, White MM, et al. Association between household and workplace smoking restrictions and adolescent smoking. JAMA 2000;284:717-22.

33 Pinilla J, Gonzales B, Barber P, et al. Smoking in young adolescents: an approach with multilevel discrete choice models. J Epidemiol Community Health 2002:56:227-32.

34 Wakefeld MA, Chaloupka FJ, Kaufman NJ, et al. Effect of restrictions on smoking at home, at school, and in public places on teenage smoking: cross sectional study. BMJ 2000;321:333-7.

35 Mumford EA, Levy DT, Romano EO. Home smoking restrictions. Problems in classification. Am J Prev Med 2004;27:126-31.

36 Patrick DL, Cheadle A, Thompson DC, et al. Validity of self-reported smoking; a review and meta-analysis. Am J Public Health 1994;84:1086-93.

37 US Department of Health and Human Services. The health benefits of smoking cessation. A report of the surgeon general. Washington, DC: US DHSS, PHS, CDC, 1990.

38 Bureau of National Affairs. Smoking in the workplace 1991. Society of human resource management. Washington, DC: Bureau of National Affairs, 1991

39 Sorensen G, Rosen A, Pinney J, et al. Worksite smoking policies in small businesses. J Occup Med 1991;33:980-4.

40 Brownson RC, Hopkins DP, Wakefield MA. Effects of smoking restrictions in the workplace. Annu Rev Public Health 2002;23:333-48.

41 Brownson RC, Hopkins DP. Policy related approaches to reducing environmental tobacco smoke exposure in the workplace. In: Work, Smoking, and Health. Atlanta, GA: Centers for Disease Control, National Institute for Occupational Safety and Health, 2002.

42 Truman BJ, Smith-Akin CK, Hinman AR, et al. Developing the guide to community preventive services; overview and rationale. Am J Prev Med 2000;18:18-26.

43 Marom D, Rissel C. Factors associated with smoke-free homes in NSW: results from the 1998 NSW health survey. Aust N Z J Public Health $2001 ; 25: 339-45$

44 Sorensen G. Smoking cessation in the workplace. What works and what is the role of occupational health. In: Work, smoking, and health. Atlanta, GA Centers for Disease Control, National Institute for Occupational Safety and Health, 2002.

45 Gilpin EA, Pierce J. California tobacco control program and potential harm reduction through reduced cigarette consumption in continuing smokers. Nicotine Tobacco Research 2002;4:S157-66

46 US Environmental Protection Agency. Local programs promoting smoke-free homes, Vol 3. Washington, DC: US EPA, http://www.epa.gov/smokefree. 